\title{
Inactive elders in Portugal . . . and other stories
}

Despite being a Roman goddess, Minerva recently showed a poor understanding of Latin (BMJ 2016;355:i6053, doi:10.1136/ bmj.i6053) when she described the fungus Candida auris as "a Latin combination of white and gold.” Aureus, as Roman scholars should know, is the Latin term for golden, whereas auris represents an ear-from which the fungus was first isolated. 